
\title{
25 Research Soure \\ Uptake of Misoprostol among women seeking abortion in Accra, Ghana
}

Eugene Kofuor Maafo Darteh ( $\square$ edarteh@ucc.edu.gh )

Research

Keywords: Abortion, Misoprostol, Induced abortions, Ghana, Accra

Posted Date: April 28th, 2020

DOl: https://doi.org/10.21203/rs.3.rs-21328/v1

License: (9) (i) This work is licensed under a Creative Commons Attribution 4.0 International License. Read Full License 


\section{Abstract}

Background: Unsafe abortions remain one of the key contributors to maternal mortality. The WHO has recommended misoprostol as a safe abortifacient which has become a popular over the counter selfadministered abortifacient in Ghana. This study sought to examine the prevalence of misoprostol uptake and model the factors associated with its uptake among 698 women seeking abortion services in the Accra Metropolis.

Methods: Univariate and multivariate analysis were done. The multivariate analysis was done using binary logistic regression to model the factors associated with misoprostol uptake and results are presented as adjusted odds ratios (AORs) with their $95 \%$ confidence intervals (Cls). $\mathrm{P}<0.05$ was considered statistically significant.

Results : The results showed that the prevalence of misoprostol uptake was $20.8 \%$. The regression analysis showed that women aged 25-34 had 0.60 lower odds of using misoprostol compared with those aged 15-24 years [OR=0.60, $\mathrm{Cl}=0.38-0.94]$. Those who can save some money had higher odds [OR=2.31, $\mathrm{Cl}=1.03-5.16]$ of using misoprostol compared with those who often do not have sufficient food. Those who were cohabiting/separated had higher odds [OR=1.83, $\mathrm{Cl}=1.09-3.06]$ of using misoprostol compared to those who were never married. Those who had 1 [OR=0.26, $\mathrm{Cl}=0.14-0.46]$ and 2 or more [OR=0.23, $\mathrm{Cl}=0.07-0.76]$ had lower odds of using misoprostol compared to those who have never had a miscarriage.

Conclusion : The prevalence of misoprostol uptake among women seeking abortion services in Accra Metropolis is relatively high. Age, socio-economic status, marital status and previous history of miscarriage are associated with misoprostol uptake. Although proven effective by various studies and recommended by the WHO, it is imperative to consider these factors in the education of women on the use of misoprostol as well as designing programmes to target women who are inclined to induce abortion in Ghana.

\section{Background}

Unsafe abortion remains one of the most critical components of reproductive health globally [1]. About 25 million (45\%) of pregnancies among women aged 15-49 are terminated unsafely out of the 55.7 million that occur annually across the globe. From this number, 24 million (97\%) happen in Low and Middle-income Countries (LMICs) predominantly with restrictive abortion laws [2, 3]. These figures are exacerbated with high unmet need for contraception especially in LMICs [4]. These unsafe abortions contribute 47,000 to the global maternal mortality cases, with 6.9 million suffering various degrees of complications [3, 4]. From those suffering complications, about 5 million in LMICs are hospitalized yearly [5]. The World Health Organization [4] defines unsafe abortion "as a procedure for terminating an unintended pregnancy carried out by either a person lacking the necessary skills or in an environment that does not conform to minimal medical standards, or both". However, about 2 decades ago, with the 
introduction and pervasive access to medical abortion drugs, there has been high ascendency in safe abortions and corresponding reductions in abortion-related morbidity and mortality $[3,6]$.

In Ghana, maternal mortality is the second highest cause of death among women of reproductive age, with approximately $20.8 \%$ of maternal deaths resulting from unsafe induced abortions [7]. Although Ghana is one of the countries which amended its abortion law in 1985 to make it more liberal; the current law permits abortion carried out by a registered medical practitioner in a registered public or private health facility. The circumstances under which abortion is permissible are: rape, defilement and incest; where the pregnancy poses substantial risk to the physical or mental health of the woman; or in cases of severe foetal anomaly [8-10]. In 2003, a policy to provide abortion care to the full extent of the law was developed. And since 2006, service delivery standards and protocols on prevention and management of unsafe abortion including provision of comprehensive abortion care have been implemented nationwide [11]. Although the law is liberal, about 70 induced abortions per 1000 performed in Ghana each year among women of reproductive age are unsafe $[10,12,13]$.

Different methods are used for the termination of pregnancies. One of such method is medical abortion which offers a vital alternative to surgical abortion for women with early pregnancies [14]. Presently, three regimens exist for medical abortion in Ghana. These are Misoprostol alone, methotrexate followed by misoprostol, and, mifepristone followed by misoprostol [15]. Misoprostol, is a synthetic analogue of the prostagland in E1 that was introduced around 1980s [16]. The WHO has certified it to be safe and effective in the first trimester for self-administration, especially in LMICs [17]. Mifepristone, followed by a prostaglandin (such as misoprostol), is considered the gold standard for medical abortion [18]. A regimen of $200 \mathrm{mg}$ mifepristone and $800 \mu \mathrm{g}$ buccal or vaginal misoprostol is $95-98 \%$ effective [19]. Various studies have proven its effectiveness [1, 20-26] and improved health care system [26] in other setting and attributed the declining complication and mortality rates associated with induced abortions in some developing countries especially in Latin America to the widespread use of misoprostol [21, 23].

Scarce but growing body of literature exist on misoprostol use in Ghana. With some focusing on morbidities associated with induced abortions among misoprostol users [10], management of incomplete abortions with misoprostol [27] and its availability and prescription in community pharmacies [14]. Despite these studies, none has focused on the prevalence and factors associated with misoprostol uptake among women seeking abortion care in an urban area in Ghana. Mindful of this gap, this study seeks to examine the prevalence and factors associated with its uptake among women in the Accra Metropolis of Ghana. Findings from such a study will help bring to bear the proportion of women using misoprostol in urban setting and factors associated with its uptake among women to aid in abortion care delivery, education and policy strengthening.

\section{Materials And Methods}

\section{Data and Sources}


The study uses data from a multi-country study entitled "the Relationship Between the use of Misoprostol and the Type and Severity of Abortion Symptoms". This paper uses data from the study conducted in Ghana. The study was a facility quantitative cross-sectional. A total of three hospitals rendering abortion services - Marie Stopes International Clinics - Ashaiman and Kokomlemle and La-General Hospitals all in the Greater Accra region, Ghana were selected for the study.

The facilities were selected from a list of all providers with at least three years of post-abortion services provision. Selection from the sampling frame was done by simple random sampling from the sampling frame stratified by length of service. Random sampling was preferred over purposive sampling to limit the possibility of bias in the selection of respondents. These facilities were selected because at the time of the study, they had large post-abortion care caseloads.

A total of 800 women aged 18 years and over coming with symptoms of an abortion who were examined in the obstetrics and gynaecology wards of the selected hospitals were recruited over a period of six months for the study after being examined by a physician. Data from a total of 698 women is used for this study given a response rate of 82 percent. A record of examination form was completed by the physician at the end of the examination. All women aged 18 and over who presented with symptoms of an abortion were asked by the provider at the end of initial examination if she was interested in being interviewed for a research study. If interested she was introduced to an interviewer, who was a female doctor or nurse in the obstetrics and gynaecology ward of the participating hospital. Research assistants were trained over a 5 - day period on how to ask questions and code answers. The interviewer obtained informed consent from the woman and if she was agreeable, the interview was carried out in a private setting. Care was taken to ensure that the interviewer did not provide care to the women admitted.

The interview focused on: brief social and demographic characteristics; method of abortion; history of attempts (for current abortion); knowledge of method; where they obtained the method; source of information; expectation of treatment after using the method and the cost of method.

The questionnaire was pre tested prior to the actual data collection. Data collection was constantly checked by the investigator at each hospital to ensure accuracy and completeness of data collected from each woman. To ensure data quality, completeness, accuracy and consistency all collected data was checked every day by the investigator and supervisor during the entire data collection period. Any quest related to clarity, ambiguity, incompleteness, misunderstanding, was solved on the following day before the next day's activities.

All questionnaires completed by the interviewer were kept in a locked filing cabinet at the hospital. At monthly intervals the completed questionnaires were transported to the office of the principal investigator. At this stage no questionnaire contained an individual identifier. All data was entered using Epi Info Version 3.5.3 and later exported to STATA for further analysis. Data quality checks were performed and any inconsistency errors were resolved by reviewing the questionnaire. Data quality checks were done during the data cleaning. 


\section{$\square$ Study variables}

Outcome variable was misoprostol use. It was a dichotomous variable derived from the question "Did you use misoprostol to stop this most recent pregnancy? The answers were Yes $=1$ and $\mathrm{No}=0$. The independent variables in the study included aged(18-24, 25-34,35-49), standard of living (Often do not have sufficient food, enough to survive, can save some money, more than sufficient), Educational level (no formal education, Primary, Junior High School, Senior High School, higher), marital status (never Married, Currently married, Cohabiting/separated), Number of children/parity (0, 1, 2 or more), Number of miscarriages $(0,1,2$ or more), Pregnancy intention (wanted, mistimed, unwanted) and contraceptive use (no, yes).

\section{Statistical analysis}

In this study both descriptive and inferential analysis were done. At the descriptive level frequencies and percentages were used to describe the respondents who participated in the study. Second, estimates of the prevalence of misoprostol use and explanatory variables are were presented across the independent variables. Afterwards a binary logistic regression model was fitted to model the strength of association among variables that were significantly associated with misoprostol use. Prior to the model fitting, Variance inflation factor (VIF) was used to check multi-collinearities between candidate variables and there was no evidence of multicollinearity. The results from the regression model were presented as adjusted odds ratios (AORs). Confidence level was held at $95 \%$ signifying level of precision. Significance levels were estimated at $p<0.05, p<0.01$ and $p<0.001$. All analysis was conducted using STATA 14.2 (StataCorp, 2014).

\section{Ethical Consideration}

The Institutional review board of the Ghana Health Service approved the study (GHS-ERC:12/11/11). The persons selected for the survey were informed of the purpose of the study, the confidentiality of the responses, the ability of the subject to decline to participate or, if participating, the right to withdraw from the interview at any stage of the research without any consequences to care or benefits they are entitled to. During the informed consent, the person was encouraged to ask questions to clarify issues regarding the study that she/he does not understand. The subject was then required to sign the informed consent form before being enrolled in the study. It was extremely important that the subject's identity was protected because of the restrictive law on abortion. Care was taken at all stages of the research to safeguard the identity of the subjects and the information they provided. The name of the women was not entered on the questionnaire. Two numbers were affixed to the questionnaire: a temporary number that was appended by the attending physician and a survey number that was allocated by the survey administrator. Upon the discharge of the woman the information from the examination form and details of the treatment of the woman were extracted from this form. The temporary number was then removed from the form and destroyed. Only those women aged 18 and over were interviewed in the study. Interviews were conducted only after the subject fully understood what she was expected to do and willing to participate by giving her consent. The interviews were conducted in private. There was a 
compensation of US\$3 a person for the survey for the time taken. All survey questionnaires were stored in a locked cabinet in the office of the principal investigator who will also be responsible for keeping the key. An additional key was kept with the assistant to the principal investigator. Survey questionnaires were to be destroyed, using paper shredder, five years after the completion of the study.

\section{Results}

\section{Socio-demographic of respondents and prevalence of misoprostol uptake}

Table 1 presents the socio-demographic characteristics of the respondents. It was observed that almost half $(48.4 \%)$ of the women who participated win the study were aged 25-34 while 10.2\% were aged 35-49. With standard of living, $59 \%$ of the women indicated that they had enough money to survive while $8.6 \%$ indicated they often do not have sufficient food. With level of education, $37.8 \%$ had completed Senior High School (SHS) while $11.9 \%$ had primary level of education. In relation to marital status, $45.3 \%$ were

never married whereas $18.2 \%$ were cohabiting/separated. The majority $(52 \%)$ of the respondents had no children whereas $23.6 \%$ had 2 or more children. It was also found that $66.9 \%, 70.8 \%$ and $82.4 \%$ respectively had never experienced miscarriages, pregnancies were wanted and were not using contraceptives. The results also show that $26.6 \%$ of those aged $18-24,23.4 \%$ of those with higher level of education, $33.9 \%$ of those who were cohabiting, $22.9 \%$ of those with no child, $27.0 \%$ of those with no experience of miscarriage and $21 \%$ of those who indicated their pregnancy were unwanted resorted to the use of misoprostol (see Table 1).

\section{Binary logistic analysis results}

Table 2 shows the results from the study on the factors associated with misoprostol among women seeking induced abortion in Accra. The results showed that women aged 25-34 had 0.60 lower odds of using misoprostol compared with those aged 18-24 years [AOR=0.60, $\mathrm{Cl}=0.38-0.94]$. Those who can save some money had higher odds $[\mathrm{AOR}=2.31, \mathrm{Cl}=1.03-5.16]$ of using misoprostol compared with those who often do not have sufficient food. Those who were cohabiting/separated had higher odds [AOR=1.83, $\mathrm{Cl}=1.09-3.06]$ of using misoprostol compared to those who were never married. Those who had $1[\mathrm{AOR}=0.26, \mathrm{Cl}=0.14-0.46]$ and 2 or more [AOR=0.23, $\mathrm{Cl}=0.07-0.76]$ had lower odds of using misoprostol compared to those who have never had a miscarriage.

\section{Discussion}

This study sought to examine the prevalence of misoprostol use and the factors associated with its uptake among women seeking abortion care in the Accra metropolis of Ghana. The study revealed that the prevalence of misoprostol uptake was $20.8 \%$. This figure, although slightly higher, is similar to the $18 \%$ reported by the GSS et al [12] in the 2017 Ghana Maternal Health survey. The figure is however, lower than the $60-83 \%$ reported in previous studies in Kumasi [10, 29]; but higher than the $12.4 \%$ observed in Nigeria [30]. The figures are however higher than those recorded in other parts of the world $(1.2 \%-1.6 \%)$ 
[31-33]. The possible explanation for the low uptake could be that women may not have understood the question or known what the terms "misoprostol" or "Cytotec" meant even if they had used the drug. Underreporting is also possible because of the restrictive laws regulating abortions in the country. The likely explanation for the high prevalence of misoprostol uptake compared to previous studies elsewhere might be as a result of the quite liberal law on abortion in Ghana. These figures confirm earlier reports that misoprostol had become a popular and relatively cheap over the counter abortifacient among women in certain parts of Ghana $[10,14,29]$.

The study observed a statistically significant association between age and the uptake of misoprostol. Specifically, those aged 25-34 had lower odds of using misoprostol compared to those aged 15-24. This finding is consistent with previous studies in Ghana $[10,13,29,34,35]$ and other parts of the world $[25,36]$, which showed that misoprostol users were younger. The probable explanation for this finding is that looking at the societal arrangements in Ghana, most women aged 15-24 are still under the control of their parents' control and therefore might resort to unsafe abortions for fear of being disowned by their parents [37; 38].

It was also found that women who could save some money were more probably to use misoprostol compared to those who often do not have sufficient food. This support previous studies in Ghana [38, 39] on the association between socio-economic status(wealth) and uptake of abortion services that have shown that women in high socio-economic status have higher odds to seek abortion services than those in lower socio-economic status. The possible explanation to this is that women from higher socioeconomic status households' richer households may be financially empowered and can afford both direct and indirect cost associated with misoprostol use [40,41].

It was also found that women who are cohabiting/separated were more likely to use misoprostol compared to those who are married. This corroborate previous studies by Schwandt et al. [42], Klutsey, and Ankomah, [43] and Oliveras, Ahiadeke, Adanu and Hill [44] found that those who sought abortion services were unmarried, divorced, or separated. However, this finding contradicts a previous study about 2 decades ago which showed that induced abortion was high among those who are married [45]. The possible explanation to this finding as stated by Klutsey and Ankomah [43] is the pervasiveness Ghanaian societal norms that frown on premarital sex and childbearing before marriage. The study also showed that those with 1 and 2 or more miscarriage had lower odds of using misoprostol compared to those who have never experienced miscarriage. The possible explanation to this finding can be situated in the health belief model and the theory of reasoned action [46, 47]. Specifically, the construct of perceived susceptibility to additional miscarriages and complications as well as the evaluation of potential impacts of an action before undertaking it.

\section{Strength And Weaknesses}

Despite the relatively large sample size, the study is fraught with some methodological limitations that are worth acknowledging. First, the cross-sectional study design, hinders the possibility of interpreting 
these factors associated with misoprostol uptake as causal. Second, as with any other study eliciting information from respondents, the reliability and validity depends on the accuracy of their responses. Third, for sensitive topics such as abortion, misreporting and underreporting can occur. In addition, there could be recall errors for questions seeking information for periods farther in the past. The research addressed these issues by building rapport with the respondents and by carefully developing and implementing the study instruments. All efforts were made to ensure privacy and confidentiality and to make the respondents comfortable. However, as in all social surveys, response biases cannot be entirely eliminated.

\section{Conclusion And Policy Implications}

The prevalence of misoprostol uptake among women seeking abortion services in Accra Metropolis is relatively high. Age, socio-economic status, marital status and previous history of miscarriage are associated with misoprostol uptake. Although proven effective by various studies and recommended by the WHO, it is imperative to consider these factors in the education of women on the use of misoprostol as well as designing programmes to target women who are inclined to induce abortion in Ghana.

\section{Declarations}

\section{Acknowledgment}

I wish to thank all the participants who agreed to participate in this study. Also, I wish to thank UNDP/UNFPA/WHO/WORLD BANK special programme of research, development and research training in human reproduction for funding this larger study from which this data was sourced.

\section{Authors' contributions}

Conception and design of study: EKMD;analysis and/or interpretation of data: EKMD; drafting the manuscript: EKMD; revising the manuscript critically for important intellectual content: EKMD; proofreading of manuscript: EKMD. I have read and approved the final manuscript for submission.

\section{Authors' information}

Department of Population and Health, University of Cape Coast, Cape Coast, Ghana (EKMD)

\section{Funding}

This study did not receive any specific funding

\section{Availability of data and materials}

Data is available upon reasonable request.

Ethics approval and consent to participate 
Institutional review board of the Ghana Health Service approved the study (GHS-ERC:12/11/11). Informed consent was obtained from all the respondents before the commencement of interviews with each respondent.

\section{Consent for publication}

Not applicable.

\section{Competing interests}

The author (s) declare that they have no competing interests.

\section{Author details}

${ }^{1}$ Department of Population and Health, University of Cape Coast, Cape Coast, Ghana

\section{Abbreviations}

AOR: Adjusted Odds Ratio; Cl: Confidence Interval; SDG: Sustainable Development Goal; WHO: World Health Organisation; GSS: Ghana Statistical Service; GHS: Ghana Health Service; VIF: Variance Inflation Factor; LMICs: Low and Middle-income Countries; SHS: Senior High School; JHS: Junior High School (SHS

\section{References}

1. Gambir K, Kim C, Necastro KA, Ganatra B, Ngo TD. Self-administered versus provider-administered medical abortion. Cochrane Database of Systematic Reviews. 2020(3).

2. Ganatra B, Gerdts C, Rossier C, Johnson Jr BR, Tunçalp Ö, Assifi A, Sedgh G, Singh S, Bankole A, Popinchalk A, Bearak J. Global, regional, and subregional classification of abortions by safety, 2010-14: estimates from a Bayesian hierarchical model. The Lancet. $2017 \mathrm{Nov}$ 25;390(10110):2372-81.

3. Singh S, Remez L, Sedgh G, Kwok L, Onda T. Abortion worldwide 2017: uneven progress and unequal access. Guttmacher Institute: guttmacher.org/report/abortionworldwide-2017 2018

4. World Health Organization: Unsafe abortion: global and regional estimates of the incidence of unsafe abortion and associated mortality in 2008. 2011, Geneva: World Health Organization, 6.

5. Singh S: Hospital admissions resulting from unsafe abortion: estimates from 13 developing countries. Lancet. 2006, 368 (9550): 1887-1892. 10.1016/S0140-6736(06)69778-X.

6. Miller S, Lehman T, Campbell M, Hemmerling A, Anderson SB, Rodriguez H, Gonzalez WV, Cordero M, Calderon V: Misoprostol and declining abortion-related morbidity in Santo Domingo, Dominican Republic: a temporal association. BJOG. 2005, 112 (9): 1291-1296. 10.1111/j.14710528.2005.00704. $x$. 
7. Der EM, Moyer C, Gyasi RK, Akosa AB, Tettey Y, Akakpo PK, Blankson A, Anim JT. Pregnancy related causes of deaths in Ghana: a 5-year retrospective study. Ghana medical journal. 2013 Dec;47(4):158.

8. Baiden F: Making safe abortion services accessible in Ghana. Journal Women's Health. 2009, 18 (12): 1923-1924. 10.1089/jwh.2009.1689.

9. Morhee R, Morhee E: Overview of the law and availability of abortion services in Ghana. Ghana Med J. 2006, 40 (3): 80-86.

10. Damalie FJ, Dassah ET, Morhe ES, Nakua EK, Tagbor HK, Opare-Addo HS. Severe morbidities associated with induced abortions among misoprostol users and non-users in a tertiary public hospital in Ghana. BMC women's health. 2014 Dec;14(1):90.

11. Ministry of Health: Prevention and management of unsafe abortion: comprehensive abortion care services, standards and protocols. 2006, Ghana: Accra: Ministry of Health

12. Ghana Statistical Service (GSS), Ghana Health Service (GHS), Macro International: Ghana Maternal Health Survey 2017. 2018, Calverton, Maryland, USA: GSS, GHS and Macro International. 2018

13. Ahiadeke C: Incidence of induced abortion in southern Ghana. International Family Planning Perspectives.2001, 27 (2): 96-108. 10.2307/2673822.

14. Ganle JK, Busia NT, Maya E. Availability and prescription of misoprostol for medical abortion in community pharmacies and associated factors in Accra, Ghana. International Journal of Gynecology \& Obstetrics. 2019 Feb;144(2):167-73.

15. Verk J, Zhang J, Olsen J. Medical abortion and the risk of subsequent adverse pregnancy outcomes. N Engl J Med. 2007; 357:648-653.

16. Juarez F, Sundaram A, Ahiadeke C, Bankole A, Singh S, Blades N. The impact of Ghana's R3M program on the provision of comprehensive abortion care services. Health Policy Plann. 2015; 30:1017-1031

17. Wilson KS, Garcia SG, Lara D. Misoprostol use and its impact on measuring abortion incidence and morbidity. Methodologies for estimating abortion incidence and abortion-related morbidity: a review. 2010:191.

18. Winikoff B, Sheldon W. Use of medicines changing the face of abortion. Int Perspect Sex Reprod Health. 2012; 38:164-166

19. Allen R, O'Brien BM. Uses of misoprostol in obstetrics and gynecology. Rev. Obstet. Gynecol. 2009; 2:159-168

20. Ting WH, Peng FH, Lin HH, Lu HF, Hsiao SM. Factors influencing the abortion interval of second trimester pregnancy termination using misoprostol. Taiwanese Journal of Obstetrics and Gynecology. 2015 Aug 1;54(4):408-11.

21. Shah IH, Weinberger MB. Expanding access to medical abortion: perspectives of women and providers in developing countries. International Journal of Gynecology \& Obstetrics. 2012 Sep;118: S1-3. 
22. Elsheikh A, Antsaklis A, Mesogitis S, Papantoniou N, Rodolakis A, Vogas E, Michalas S. Use of misoprostol for the termination of second trimester pregnancies. Archives of gynecology and obstetrics. 2001 Nov 1;265(4):204-6.

23. Sherris J, Bingham A, Burns MA, Girvin S, Westley E, Gomez PI: Misoprostol use in developing countries: results from a multicountry study. Int J Gynaecol Obstet. 2005, 88 (1): 76-81.

10.1016/j.ijgo.2004.09.006

24. Goldstone P, Michelson J, Williamson E. Early medical abortion using low-dose mifepristone followed by buccal misoprostol: a large Australian observational study. Medical journal of Australia. 2012 Sep;197(5):282-6.

25. Billings, DL. Misoprostol alone for early medical abortion in a Latin American clinic setting. Reproductive health matters, 12(sup24), 2004.57-64.

26. Áhman E, Shah IH. New estimates and trends regarding unsafe abortion mortality. International Journal of Gynecology \& Obstetrics. 2011 Nov;115(2):121-6.

27. Taylor J, Diop A, Blum J, Dolo O, Winikoff B. Oral misoprostol as an alternative to surgical management for incomplete abortion in Ghana. International Journal of Gynecology \& Obstetrics. 2011 Jan 1;112(1):40-4.

28. Sacdpraseuth, A., P. Soukhaphonh, C. Kommanivong and C. Banechith. 2005. Hospital-based Descriptive Study of Illegally Induced Abortions-related Mortality and Morbidity and it's Cost on Health Services, Report submitted to UNFPA.

29. Konney TO, Danso KA, Odoi AT, Opare-Addo HS, Morhe ES: Attitude of women with abortion-related complications toward provision of safe abortion services in Ghana. J Womens Health (Larchmt). 2009, 18 (11): 1863-1866. 10.1089/jwh.2008.1190.

30. Bello FA, Fawole B, Oluborode B, Awowole I, Irinyenikan T, Awonuga D, Loto O, Fabamwo A, Guest P, Ganatra B. Trends in misoprostol use and abortion complications: A cross-sectional study from nine referral hospitals in Nigeria. PloS one. 2018;13(12).

31. Kerestes C, Sheets K, Stockdale CK, Hardy-Fairbanks AJ. Prevalence, attitudes and knowledge of misoprostol for self-induction of abortion in women presenting for abortion at Midwestern reproductive health clinics. Sexual and reproductive health matters. 2019 Jan 1;27(1):118-25.

32. Jones How commonly do US abortion patients report attempts to self-induce? Am J Obstet Gynecol. 2011 Jan;204(1):23. e1-23. e4. PubMed PMID: 20863478. doi: 10.1016/j.ajog.2010.08.019

33. Grossman D, Hendrick E, Fuentes L, White K, Hopkins K, Stevenson A, Lopez CH, Yeatman S, Potter JE. Knowledge, opinion and experience related to abortion self-induction in Texas. Contraception. 2015 Oct 1;92(4):360-1.

34. Adanu RM, Ntumy MN, Tweneboah E. Profile of women with abortion complications in Ghana. Tropical Doctor. 2005 Jul 1;35(3):139-42.

35. Sedgh G. Abortion in Ghana. Issues in brief (Alan Guttmacher Institute). 2010 Jul (2):1-4.

36. Henshaw SK, Adewole I, Singh S, Bankole A, Oye-Adeniran B, Hussain R. Severity and cost of unsafe abortion complications treated in Nigerian hospitals. International family planning perspectives. 
2008 Mar 1:40-50.

37. Iboudo PGC, Somda SMA, Sundby J. Key determinants of induced abortion in women seeking postabortion care in hospital facilities in Ouagadougou, Burkina Faso. Int J Women's Health. 2014; 6:565-72.

38. Guttmacher Institute. Abortion in Ghana. Guttmacher Institute, 125 Maiden Lane New York, NY 10038 USA, 2013. https://www.guttmacher.org/pubs/FB-Abortion-in-Ghana.pdf.

39. Adjei G, Enuameh Y, Asante KP, Baiden F, Nettey OE, Abubakari S, Mahama E, Gyaase S, Owusu-Agyei S. Predictors of abortions in rural Ghana: a cross-sectional study. BMC public health. 2015 Dec;15(1):202.

40. Ouédraogo R, Sundby J. Social determinants and access to induced abortion in Burkina Faso: from two case studies. Obstetrics and gynecology international. 2014;2014.

41. Puri M, Lamichhane P, Harken T, Blum M, Harper CC, Darney PD, Henderson JT. "Sometimes they used to whisper in our ears": health care workers' perceptions of the effects of abortion legalization in Nepal. BMC Public Health. 2012 Dec;12(1):297.

42. Schwandt HM, Creanga AA, Danso KA, Adanu RM, Agbenyega T, \& Hindin MJ. A comparison of women with induced abortion, spontaneous abortion and ectopic pregnancy in Ghana. Contraception. 2011;84(1), 87-93.

43. Klutsey EE, \& Ankomah A. Factors associated with induced abortion at selected hospitals in the Volta Region, Ghana. International journal of women's health. 2014;6, 809.

44. Oliveras E, Ahiadeke C, Adanu RM, \& Hill AG. Clinic-based surveillance of adverse pregnancy outcomes to identify induced abortions in Accra, Ghana. Studies in Family Planning. 2008;39(2), 133140.

45. Biddlecom A. Unsafe abortion in Kenya. Issues in brief (Alan Guttmacher Institute). 2008;(4), 1-4.

46. Andersen R, Newman JF. Societal and individual determinants of medical care utilization in the United States. The Milbank Memorial Fund Quarterly. Health and Society. 1973 Jan 1:95-124.

47. Albarracin D, Ajzen I. Predicting and changing behavior: A reasoned action approach. Prediction and Change of Health Behavior: Applying the Reasoned Action Approach. Lawrence Erlbaum Associates, Mahwah, NJ. 2007:3-21.

\section{Tables}

Table 1: Background characteristics and prevalence of misoprostol uptake among women 


\begin{tabular}{|c|c|c|c|c|}
\hline \multirow[t]{2}{*}{ Variable } & \multirow[t]{2}{*}{$\mathrm{N}=698$} & \multirow[t]{2}{*}{$\%$} & \multicolumn{2}{|c|}{ Misoprostol use } \\
\hline & & & No & Yes \\
\hline Prevalence & & & 79.2 & 20.8 \\
\hline \multicolumn{5}{|l|}{ Age (years) } \\
\hline $18-24$ & 289 & 41.4 & 73.4 & 26.6 \\
\hline $25-34$ & 338 & 48.4 & 82.8 & 17.2 \\
\hline $35-49$ & 71 & 10.2 & 85.9 & 14.1 \\
\hline \multicolumn{5}{|l|}{ Standard of living } \\
\hline Often do not have sufficient food & 60 & 8.6 & 76.7 & 23.3 \\
\hline Enough to survive & 409 & 58.6 & 82.6 & 17.4 \\
\hline Can save some money & 165 & 23.6 & 75.8 & 24.2 \\
\hline More than sufficient & 64 & 9.2 & 68.8 & 31.3 \\
\hline \multicolumn{5}{|l|}{ Educational level } \\
\hline Primary & 83 & 11.9 & 80.7 & 19.3 \\
\hline Junior High School & 214 & 30.7 & 78.0 & 22.0 \\
\hline Senior High School & 264 & 37.8 & 81.1 & 18.9 \\
\hline Higher & 137 & 19.6 & 76.6 & 23.4 \\
\hline \multicolumn{5}{|l|}{ Marital status } \\
\hline Never Married & 316 & 45.3 & 77.5 & 22.5 \\
\hline Currently married & 255 & 36.5 & 87.8 & 12.2 \\
\hline Cohabiting/separated & 127 & 18.2 & 66.1 & 33.9 \\
\hline \multicolumn{5}{|l|}{ Number of children } \\
\hline 0 & 363 & 52.0 & 77.1 & 22.9 \\
\hline 1 & 170 & 24.4 & 82.4 & 17.7 \\
\hline $2+$ & 165 & 23.6 & 80.6 & 19.4 \\
\hline \multicolumn{5}{|l|}{ Number of miscarriages } \\
\hline 0 & 467 & 66.9 & 73.0 & 27.0 \\
\hline 1 & 185 & 26.5 & 91.4 & 8.7 \\
\hline $2+$ & 46 & 6.6 & 93.5 & 6.5 \\
\hline \multicolumn{5}{|l|}{ Pregnancy intention } \\
\hline Wanted & 494 & 70.8 & 78.5 & 21.5 \\
\hline Mistimed & 99 & 14.2 & 82.8 & 17.2 \\
\hline Unwanted & 105 & 15.0 & 79.1 & 21.0 \\
\hline \multicolumn{5}{|l|}{ Contraceptive use } \\
\hline No & 575 & 82.4 & 78.1 & 21.9 \\
\hline Yes & 123 & 17.6 & 84.6 & 15.5 \\
\hline
\end{tabular}

Source: Field work, 2012

Table 2: Multivariate analysis of the determinants of misoprostol uptake among women seeking abortion in Accra, Ghana 


\begin{tabular}{|c|c|c|c|c|}
\hline Variable & AOR & $95 \% \mathrm{CI}$ & & P-value \\
\hline Age & & Lower bound & Upper bound & \\
\hline $18-24$ & Ref & & & \\
\hline $25-34$ & $0.60 *$ & 0.38 & 0.94 & 0.026 \\
\hline $35+$ & 0.63 & 0.26 & 1.53 & 0.311 \\
\hline Standard of living & & & & \\
\hline Often do not have sufficient food & Ref & & & \\
\hline Enough to survive & 1.09 & 0.53 & 2.25 & 0.811 \\
\hline Can save some money & $2.31 *$ & 1.03 & 5.16 & 0.042 \\
\hline More than sufficient & 2.31 & 0.92 & 5.81 & 0.075 \\
\hline Educational level & & & & \\
\hline Primary & Ref & & & \\
\hline JHS & 0.96 & 0.48 & 1.94 & 0.915 \\
\hline SHS & 0.86 & 0.43 & 1.72 & 0.665 \\
\hline Higher & 1.01 & 0.46 & 2.22 & 0.986 \\
\hline Marital status & & & & \\
\hline Never married & Ref & & & \\
\hline Currently married & 0.57 & 0.32 & 1.01 & 0.054 \\
\hline Cohabiting/separated & $1.83^{*}$ & 1.09 & 3.06 & 0.022 \\
\hline Number of children & & & & \\
\hline 0 & Ref & & & \\
\hline 1 & 1.02 & 0.61 & 1.68 & 0.954 \\
\hline $2-5$ & 1.62 & 0.86 & 3.05 & 0.136 \\
\hline Number of miscarriages & & & & \\
\hline 0 & Ref & & & \\
\hline 1 & $0.26^{* * *}$ & 0.14 & 0.46 & 0.000 \\
\hline $2-5$ & $0.23^{*}$ & 0.07 & 0.76 & 0.017 \\
\hline Pregnancy intention & & & & \\
\hline Wanted & Ref & & & \\
\hline Mistimed & 0.82 & 0.42 & 1.60 & 0.568 \\
\hline Unwanted & 0.92 & 0.47 & 1.83 & 0.822 \\
\hline Contraceptive use & & & & \\
\hline No & Ref & & & \\
\hline Yes & 0.57 & 0.28 & 1.15 & 0.114 \\
\hline $\mathrm{N}$ & 698 & & & \\
\hline $\mathrm{R}^{2}$ & 0.108 & & & \\
\hline
\end{tabular}

Source: ${ }^{*} p<0.05,{ }^{* *} p<0.01,{ }^{* * *} p<0.001$, AOR $=$ Adjusted Odds Ratio CI=Confidence Interval; Ref $=$ reference category 
Page 15/15 